\title{
FAKTOR INFRASTRUKTUR DALAM PEMBANGUNAN EKONOMI KOTA MATARAM
}

\section{SANTIAN ${ }^{1)}$,PUTU KARISMAWAN ${ }^{2)}$,BAIQ SARIPTA W.M ${ }^{3)}$}

\author{
Fakultas Ekonomi Universitas Mataram \\ e-mail: ${ }^{1)}$ santiana0710@gmail.com,${ }^{2)}$ putukarismawan@gmail.com, ${ }^{3)}$ itamazka@gmail.com
}

\begin{abstract}
ABSTRAK
Penelitian ini berjudul "Faktor Infrastruktur Dalam Pembangunan Ekonomi Kota Mataram". Tujuan dari penelitian ini adalah untuk melihat peranan infrastruktur jalan, infrastruktur listrik dan infrastruktur pendidikan, baik secara parsial maupun secara simultan dalam pembangunan ekonomi Kota Mataram. Indikator Infrastruktur dalam penenlitian ini meliputi jalan, listrik dan Pendidikan. Produk Domestik Regional Bruto (PDRB) atas dasar agarberlaku dijadikan indikator ekonomi. Data infrastruktur dan PDRB yang dianalisis meliputi kurun waktu 2001-2016.

Hasil analisis menunjukkan bahwa secara simultan infrastuktur jalan, listrik dan pendidikan berperan signifikan dalam pembangunan ekonomi kota Mataram. secara parsial infrastruktur jalan dan infrastruktur listrik berperan signifikan dalam pembangunan ekonomi Kota Mataram.
\end{abstract}

Kata Kunci : Infrastruktur Jalan, Infrastruktur Listrik, Infrastruktur Pendidikan, Pertumbuhan Ekonomi.

\section{ABSTRACT}

This study is entitled "Infrastructure Factors in the Economic Development of the City of Mataram". The purpose of this study is to look at the role of road infrastructure, electricity infrastructure and education infrastructure, both partially and simultaneously in the economic development of the City of Mataram. Infrastructure indicators in this study include roads, electricity and education. Gross Regional Domestic Product (GRDP) on the basis of being used as an economic indicator. Infrastructure data and GRDP analyzed cover the period 2001-2016.

The results of the analysis show that simultaneous road, electricity and education infrastructure play a significant role in the economic development of the city of Mataram. partially road infrastructure and electricity infrastructure play a significant role in the economic development of the City of Mataram.

Keywords: Road Infrastructure, Electric Infrastructure, Infrastructure Education, Economic Growth.

\section{PENDAHULUAN}

Infrastruktur merupakan roda penggerak kemajuan ekonomi, sebagai lokomotif pembangunan nasional dan daerah. Secara ekonomi makro ketersediaan infrastruktur mempengaruhi marginal productivity of private capital. Secara ekonomi mikro, ketersediaan infrastruktur berpengaruh terhadap pengurangan biaya produksi (Arafah, 2017:1). Infrastruktur juga berpengaruh penting bagi peningkatan kualitas hidup dan kesejahteraan manusia serta akan meningkatkan investasi dan pertumbuhan ekonomi, pertumbuhan ekonomi ini serta banyaknya investasi yang masuk akan menyerap tenaga kerja. Infrastruktur yang baik juga akan merangsang peningkatan pendapatan masyarakat, karena aktifitas ekonomi yang semakin meningkat sebagai akibat mobilitas faktor produksi dan aktivitas perdagangan yang semakin tinggi.

Solow dalam teori pertumbuhan ekonomi neo klasik, pertumbuhan ekonomi berasal dari tiga faktor berikut: peningkatan dalam kuantitas dan kualitas pekerja (labor), kenaikan dalam kapital atau modal (melalui tabungan dan investasi) dan peningkatan dalam teknologi. Setiap peningkatan pada jumlah tenaga kerja, kapital dan teknologi akan memengaruhi perubahan pada tingkat output yang dihasilkan. Modal yang dimaksud Sollow tersebut salah satunya berasal dari sektor infrastruktur atau investasi fisik. Keberadaan infrastruktur akan mendorong terjadinya peningkatan produktivitas bagi faktor-faktor produksi, dan sebaliknya apabila mengabaikannya akan menurunkan produktivitas. Infrastruktur merupakan roda 
penggerak pertumbuhan ekonomi. Ketidak cukupan infrastruktur merupakan salah satu kunci terjadinya hambatan bagi pertumbuhan ekonomi yang lebih cepat.

Infrastruktur dapat dibedakan menjadi beberapa kategori, The World Bank memberikan batasan infrastruktur menjadi tiga bagian, yaitu infrastruktur ekonomi, sosial dan institusi. Infrastruktur ekonomi merupakan aset fisik yang diperlukan untuk menunjang aktivitas ekonomi baik dalam produksi maupun konsumsi fital, meliputi public utilities (tenaga, telekomunikasi, air minum, sanitasi dan gas), public work (jalan, bendungan, kanal, saluran irigasi dan drainase) serta sektor transportasi (jalan, rel kereta api, angkutan pelabuhan, lapangan terbang dan sebagainya). Infrastruktur sosial, merupakan aset yang mendukung kesehatan dan keahlian masyarakat, meliputi pendidikan (sekolah dan perpustakaan), kesehatan (rumah sakit dan pusat kesehatan), perumahan dan rekreasi (taman, museum dan lain-lain). Terakhir adalah Infrastruktur administrasi/institusi, meliputi penegakan hukum, kontrol administrasi dan koordinasi serta kebudayaan.

Kota Mataram yang sebagai pusat jasa, perdagangan, serta pusat perekonomian di Provinsi Nusa Tenggara Barat. Dalam upaya menunjang aktivitas perekonomian tersebut dibutuhkan infrastruktur yang memadai sehingga akan lebih memudahkan para pelaku ekonomi untuk berinteraksi.

Ketersediaan infrastruktur ekonomi seperti jalan, air bersih dan listrik di Kota Mataram berpengaruh secara langsung maupun tidak langsung terhadap produktivitas ekonomi, seperti peningkatan jumlah output yang dihasilkan, ketersediaan kesempatan kerja, serta perkembangan sektor-sektor ekonomi yang pada akhirnya akan mempengaruhi pertumbuhan ekonomi disuatu wilayah.

Selain itu peran infrastrukur sosial seperti pendidikan dapat memberikan kontribusi pada pertumbuhan ekonomi, bahwa pendidikan akan melahirkan tenaga kerja yang produktif, karena memiliki kompetensi, pengetahuan, dan keterampilan yang memadai. Sedangkan, nilai ekonomi kesehatan terletak pada sumbangannya dalam menyediakan tenaga kerja yang berkualitas untuk pertumbuhan ekonomi, infrastruktur merupakan salah satu investasi/pendapatan daerah (Hapsari, 2011).

Pertumbuhan ekonomi menjadi indikator untuk melihat hasil pembangunan yang telah dilakukan dan menentukan arah pembangunan di masa yang akan datang, pertumbuhan ekonomi Kota Mataram menunjukan adanya pertumbuhan meskipun berfluktuasi namun masih stabil.

Kontribusi infrastruktur baik infrastruktur ekonomi dan sosial memiliki pengaruh yang relatif cukup besar terhadap pertumbuhan ekonomi Kota Mataram dalam menunjang aktifitas ekonomi. Akan tetapi meskipun demikian infrastruktur di Kota Mataram masih harus lebih banyak berbenah terutama mengenai infrastruktur ekonomi dan sosial. Dimana tingi volume kendaraan serta kepadatan penduduk yang semakin tinggi dengan kebutuhan yang semakin meningkat sehingga kondisi infrastruktur harus bisa mengimbangi dengan dalam menyediakan fasilitas publik yang layak.

\section{Rumusan Masalah}

Dari uraian di atas dirumuskan permasalahan adalah : apakah secara parsial dan simultan infrastruktur jalan, listrik dan infrastruktur pendidikan berperan dalam pembangunan ekonomi Kota Mataram.

\section{Tujuan Penelitian}

Penelitian ini bertujuan untuk melihat peranan infrastruktur jalan, infrastruktur listrik dan infrastruktur pendidikan, baik secara parsial maupun secara simultan dalam pembangunan ekonomi Kota Mataram

\section{KERANGKA KONSEPTUAL}

Infrastruktur ekonomi maupun sosial merupakan masalah utama suatu wilayah dimana jika tidak diperhatikan maka akan maka akan menyebabkan perlambatan pertumbuhanekonomi. Investasi prasarana infrastruktur merupakan suatu yang mempunyai porsi yang sangat besar dari total pengeluaran pemerintah. Ini menunjukkan bahwa besarnya, peran pemerintah dalam pengadaan infrastruktur. Infrastruktur Jalan, infrastruktur listrik, infrastruktur pendidikan memiliki peran yang sangat penting bagi pertumbuhan ekonomi, karena hal ini dapat meningkatklan kesejahteraan, produktivitas ekonomi yang tinggi bagi pertumbuhan itu sendiri, sehingga akan diperoleh kapasitas produktif yang tinggi. Berdasarkan penjelasan sebelumnya maka kerangka pikir untuk penelitian ini sebagai berikut: 


\section{Gambar 1. Kerangka Konseptual}

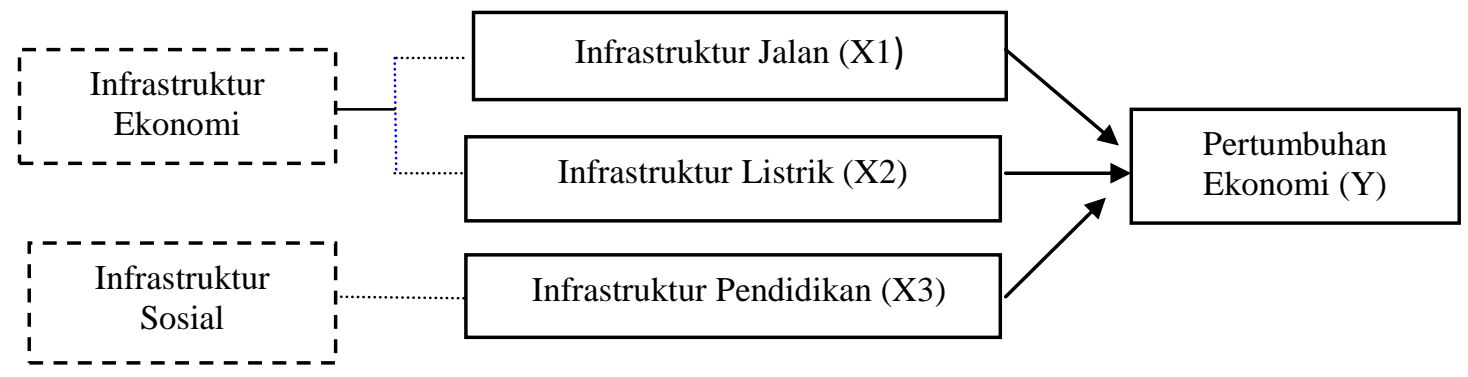

Berdasarkan kerangka konseptual di atas, terdapat beberapa faktor yang berfungsi sebagai variabel bebas yakni infrasruktur jalan (X1), infrasruktur listrik (X2), dan infrasruktur pendidikan (X3). Sedangkan variabel terikatnya yakni pertumbuhan ekonomi (Y).

\section{Hipotesis}

Berdasarkan variabel yang diambil dalam kerangka pemikiran teoritis maka hipotesa dalam penelitian ini adalah sebagai berikut :

1. Diduga infrastruktur jalan berpengaruh signifikan terhadap pertumbuhan ekonomi di Kota Mataram.

2. Diduga infrastruktur listrik berpengaruh signifikan terhadap pertumbuhan ekonomi di Kota Mataram.

3. Diduga infrastruktur pendidikan berpengaruh signifikan terhadap pertumbuhan ekonomi di Kota Mataram.

4. Diduga infrastruktur jalan, listrik, dan pendidikan secara bersama-sama berpengaruh terhadap pertumbuhan ekonom di Kota Mataram.

\section{METODE PENELITIAN}

\section{Jenis Penelitian}

Jenis penelitian yang digunakan adalah penelitian ekplanatori dengan pendekatan kuantitatif. Adapun penelitian eksplanatori menurut Sugiono (2006) adalah penelitian yang menjelaskan hubungan kausal antara variabel-variabel yang mempengaruhi hipotesis. Pada penelitian ini minimal terdapat dua variabel yang dihubungkan dan penelitian ini berfungsi menjelaskan, meramalkan, dan mengontrol suatu gejala. Oleh karena itu dalam penelitian ini nantinya akan dijelaskan mengenai adanya hubungan interaktif atau timbang balik antara variabel yang akan diteliti dan sejauh mana hubungan tersebut saling mempengaruhi. Alasan utama pemilihan jenis penelitian ini adalah untuk menguji hipotesis yang diajukan agar dapat menjelaskan pengaruh variabel bebas terhadap variabel terikat.

\section{Lokasi dan Waktu Penelitian}

Tempat penelitian ini mengambil lokasi di Kota Mataram berdasarkan pertimbangan yaitu bahwa pertumbuhan ekonomi Kota Mataram mengalami pertumbuhan ekonomi yang fluktuatif dan di tahun 2016 menunjukan peningkatan pertumbuhan ekonomi. Waktu penelitian yaitu dari tahun 2001 hingga tahun 2016, berdasarkan ketersediaan data dan menghindari penelitian yang sama untuk memenuhi syarat data agar dapat diperoleh dan dioleh dengan akurat.

\section{Teknik Pengumpulan Data}

Teknik pengumpulan data dengan studi kepustakaan dan dokumentasi

\section{Jenis dan Sumber Data}

Jenis data yang digunakan dalam penelitian ini adalah data sekunder yang bersifat kuantitatif berupa time series tahun 2001 sampai dengan tahun 2016, yang bersumber dari data sekunder . Menurut Sugiono (2006) data sekunder adalah sumber data yang tidak langsung memberikan data kepada pengumpulan, data sekunder bersifat mendukung keperluan data primer seperti buku-buku, literatur, dan bacaan yang berkaitan 
dengan pengaruh infrastruktur terhadap pertumbuhan ekonomi. Data diperoleh dari beberapa sumber, seperti BPS Provinsi NTB dan BPS Kota Mataram.

\section{Identifikasi Dan Klasifikasi Variabel}

\section{Identifikasi Variabel}

Produk Domestik Regional Bruto atas dasar harga berlaku (Y), Infrastruktur Jalan (X1), Infrastruktur Listrik (X2), Infrastruktur pendidikan (X3)

\section{Klasifikasi Variabel}

a. Variabel bebas (independen variabel) atau variabel tidak terikat $(\mathrm{x})$ dalam penelitian ini terdiri dari 3 (Tiga) data kuantitatif yaitu infrastruktur jalan, infrastruktur listrik, dan infrastruktur pendidikan.

b. Variabel terikat (dependen variabel) atau variabel terikat (Y) dalam penelitian ini adalah PDRB Kota Matarama atas Dasar harga Berlaku.

\section{Devinisi Operasional Variabel}

a. PDRB adalah PDRB atas dasar harga berlaku dalam satuan juta rupiah tahun 2001-2016 di Kota Mataram.

b. Infrastruktur Jalan yang diteliti adalah jumlah keseluruhan panjang jalan yang dilihat dari kondisi jalan baik dalam kodisi baik, sedang, rusak dan rusak berat yang tersedia pada tahun yang bersangkutan dalam satuan Km tahun 2001-2016 di Kota Mataram.

c. Infrastruktur Listrik adalah infrastruktur dasar yang harus dimiliki setiap daerah untuk mencapai tujuan kesejahteraan dan kemajuan suatu daerah. Data yang digunakan dalam penelitian ini adalah jumlah produksi listrik yang disalurkan PLN dalam satuan KWH tahun 2001-2016 di Kota Mataram.

d. Infrastruktur Pendidikan adalah infrastruktur sosial, yang di teliti adalah jumlah seluruh sarana pendidikan baik pada tingkat pendidikan TK, SD, SMP, SMA maupun SMK dalam satuan unit tahun 2001-2016 di Kota Mataram.

\section{Metode Analisis Data}

data dianalisis dengan regresi linear berganda, dengan model sebagai berikut :

$$
Y=\beta 0+\beta 1 X 1+\beta 2 X 2+\beta 3 X 3+e i
$$

dimana $: Y=P D R B$ Atas Dasar Harga Berlaku. $\beta 0=$ Intercept atau Konstanta $\beta \mathrm{i}=$ koefisien Regresi, $\mathrm{X}_{1}=$ Infrastruktur Jalan, $\mathrm{X}_{2}=$ Infrastruktur Listrik, $\mathrm{X}_{3}=$ Infrastruktur endidikan pendidikan dan $\mathrm{e}_{\mathrm{i}}=$ Eror term

Dalam penelitian untuk melihat pengaruh infrastruktur jalan, infrastruktur listrik, infrastruktur pendidikan terhadap pertumbuhan ekonomi di Kota Mataram digunakan model analisis Linear Berganda dimana pengujian akan dilakukan dalam dua (2) tahap. Tahap yang perrtama dengan melakukan pengujian statistik melalui uji parsial dan uji simultan, kemudian pada tahap kedua akan dilakukan Uji kriteria ekonometrik.

\section{HASIL DAN PEMBAHASAN}

\section{Hasil}

\section{Luas dan Batas Wilayah Administrasi}

Kota Mataram memiliki luas daratan $61,30 \mathrm{Km} 2(6,130 \mathrm{Ha})$ dan $56,80 \mathrm{Km} 2$ perairan laut serta garis pantai sepanjang $9 \mathrm{~km}$. Luas wilayah Kota Mataram tersebut hanya 0,30 persen dari luas Provinsi NTB secara keseluruhan yaitu 20.153,15 Km², sehingga menjadikan Kota Mataram sebagai kota dengan wilayah terkecil dari 10 kabupaten/kota yang ada di Provinsi NTB.

Secara administrasi Kota Mataram terbagi dalam 6 wilayah kecamatan, 50 kelurahan dan 322 lingkungan, dengan wilayah kecamatan terluas adalah Kecamatan Selaparang dengan luas $10,77 \mathrm{~km}^{2}$ dan luas wilayah terkecil adalah Kecamatan Ampenan dengan luas wilayah 9,46 km², sebagaimana terlihat pada tabel berikut ini. 
Tabel 1. Luas Wilayah, Jumlah Kelurahan dan Lingkungan Menurut Kecamatan di Kota Mataram Tahun 2016

\begin{tabular}{|l|l|c|c|c|c|}
\hline Nomor & Kecamatan & $\begin{array}{c}\text { Jumlah } \\
\text { Kelurahan }\end{array}$ & $\begin{array}{c}\text { Jumlah } \\
\text { Lingkungan }\end{array}$ & $\begin{array}{l}\text { Luas Wilayah } \\
\left(\mathrm{Km}^{2}\right)\end{array}$ & $\begin{array}{l}\text { Persentase } \\
(\%)\end{array}$ \\
\hline 1 & Ampenan & 10 & 55 & 9,46 & 15,43 \\
\hline 2 & Cakranegara & 10 & 72 & 9,67 & 15,77 \\
\hline 3 & Sekarbela & 5 & 35 & 10,32 & 16,84 \\
\hline 4 & Mataram & 9 & 55 & 10,76 & 17,55 \\
\hline 5 & Selaparang & 9 & 61 & 10,77 & 17,57 \\
\hline 6 & Sandubaya & 7 & 44 & 10,32 & 16,84 \\
\hline Jumlah & & $\mathbf{5 0}$ & $\mathbf{3 2 2}$ & $\mathbf{6 1 , 3 0}$ & $\mathbf{1 0 0 , 0 0}$ \\
\hline
\end{tabular}

Sumber : BPS Kota Mataram, 2016

\section{Produk Domestik Regional Bruto (PDRB) Kota Mataram}

Dengan ditetapkannya Kota Mataram sebagai simpul utama transportasi serta kegiatan perdagangan dan jasa skala regional, sangat berdampak terhadap pertumbuhan ekonomi terhadap capaian PDRB tahun 2011-2016 dapat dilihat pada tabel di bawah ini.

Tabel 2. PDRB Atas Dasar Harga Berlaku (Juta Rupiah) Kota Mataram Tahun 2001-2016

\begin{tabular}{|c|c|c|c|}
\hline Tahun & PDRB Berlaku & Tahun & PDRB Berlaku \\
\hline 2001 & 1164448 & 2009 & 4140353 \\
\hline 2002 & 1372342 & 2010 & 4824881 \\
\hline 2003 & 1513545 & 2011 & 5495137 \\
\hline 2004 & 2292383 & 2012 & 6092929 \\
\hline 2005 & 2312215 & 2013 & 10153328 \\
\hline 2006 & 2661939 & 2014 & 11634045 \\
\hline 2007 & 3078195 & 2015 & 13219267 \\
\hline 2008 & 3624338 & 2016 & 14805416 \\
\hline
\end{tabular}

Sumber: BPS Kota Mataram, 2016

Pada Tabel 2 bahwa PDRB tahun 2001-2016 mengalami kenaikan setiap tahunnya, kenaikan cukup signifikan terjadi pada tahun 2013 sebesar Rp 10153328 juta rupiah dibandingkan tahun sebelumnya dan kenaikan terbesar terjadi pada tahun 2016 yaitu sebesar Rp 14805416 juta rupiah hal ini didorong oleh berbagai faktor yang ada termasuk faktor infrastruktur.

\section{Infrastruktur Jalan}

Tabel 3. Jumlah Panjang Jalan (Km) Menurut Kondisi Jalan Tahun 2001 - 2016

\begin{tabular}{|c|c|c|c|}
\hline Tahun & Panjang Jalan $(\mathrm{Km})$ & Tahun & Panjang Jalan $(\mathrm{Km})$ \\
\hline 2001 & 307,588 & 2009 & 288,805 \\
\hline 2002 & 243,760 & 2010 & 303,346 \\
\hline 2003 & 264,730 & 2011 & 310,406 \\
\hline 2004 & 234,100 & 2012 & 319,715 \\
\hline 2005 & 266,600 & 2013 & 333,918 \\
\hline 2006 & 268,376 & 2014 & 333,918 \\
\hline 2007 & 274,200 & 2015 & 379,732 \\
\hline 2008 & 287,957 & 2016 & 400,063 \\
\hline
\end{tabular}

Sumber: Kota Mataram Dalam Angka 2016 (diolah)

Pada Tabel 3 ditunjukan bahwa jumlah panjang jalan berdasarkan data kondisi jalan baik pada kondisi jalan baik, sedang, rusak hingga rusak berat bahwa dapat dilihat dimana pada tahun 2001 sampai tahun 2016 mengalami peningkatan dalan jumlah panjang jalan di Kota Mataram dengan besar jumlah panjang jalan terbesar pada tahun 2016 yaitu 400,063 Km walaupun pada tahun 2004 panjang jalan Kota Mataram mengalami penurunan dari tahun sebelumnya yaitu sebesar $234,1 \mathrm{Km}$. 


\section{Infrastruktur Listrik}

Tabel 4. Jumlah Produksi Listrik yang Terdistribusikan di Kota Mataram Tahun 2004-2016 (Kwh)

\begin{tabular}{|c|c|c|c|}
\hline Tahun & Disalurkan $(\mathrm{KWH})$ & Tahun & Disalurkan $(\mathrm{KWH})$ \\
\hline 2001 & 278.111 .187 & 2009 & 429.269 .426 \\
\hline 2002 & 300.520 .285 & 2010 & 508.525 .751 \\
\hline 2003 & 25.989 .100 & 2011 & 644.828 .332 \\
\hline 2004 & 320.432 .353 & 2012 & 755.167 .749 \\
\hline 2005 & 346.912 .014 & 2013 & 888.202 .141 \\
\hline 2006 & 387.572 .427 & 2014 & 1.017 .612 .823 \\
\hline 2007 & 1.125 .600 & 2015 & 1.109 .106 .037 \\
\hline 2008 & 429.269 .426 & 2016 & 1.253 .296 .443 \\
\hline
\end{tabular}

Sumber:Mataram Dalam Angka 2016 (diolah)

Pada Tabel 4 menunjukkan bahwa peningkatan distribusi energi listrik di Kota Mataram mengalami peningkatan yang signifikan dengan ditujukkan untuk meningkatkan kesejahteraan masyarakat dan mendorong kegiatan ekonomi, khususnya sektor industri. Dari tabel diatas dapat dilihat, distribusi energi listrik dari tahun 2001-2016 mengalami peningkatan walaupun terjadi penurunan yang signifikan pada tahun 2007 sebesar 1.125.600 Kwh dan distribusi terbesar yaitu pada tahun 2016 sebesar 1.253.296.443 Kwh.

\section{Infrastruktur Pendidikan}

Berdasarkan data yang diperolah dari Badan Pusat Statistik Sumatera Utara, tercatat jumlah Sekolah baik tingkat TK, SD, SMP, SMA, maupun SMK yang berada di Kota Mataram. Berikut tabel jumlah sekolah Kota Mataram tahun 2001-2016 dibawah ini.

Tabel 5.Jumlah Sekolah Kota Mataram (Unit) Tahun 2001 - 2016

\begin{tabular}{|c|c|c|c|}
\hline Tahun & Jumlah Sekolah (Unit) & Tahun & Jumlah Sekolah (Unit) \\
\hline 2001 & 294 & 2009 & 326 \\
\hline 2002 & 284 & 2010 & 328 \\
\hline 2003 & 294 & 2011 & 340 \\
\hline 2004 & 294 & 2012 & 343 \\
\hline 2005 & 301 & 2013 & 343 \\
\hline 2006 & 295 & 2014 & 343 \\
\hline 2007 & 309 & 2015 & 343 \\
\hline 2008 & 323 & 2016 & 345 \\
\hline
\end{tabular}

Sumber: Kota Mataram Dalam Angka 2016 (diolah)

Berdasarkan Tabel 5 bahwa jumlah sekolah baik Negeri maupun Swasta dari tahun 2001-2016 mengalami peningkatan, akan tetapi pada tahun 2012-2015 jumlah sekolah Kota Mataram tetap dan tidak mengalami peningkatan yaitu sebesar 343 unit sekolah dan pada tahun 2015 jumlah sekolah di kota mataram mengalami kenaikan tidak terlalu besar yaitu sebesar 345 unit sekolah.

\section{Analisis Data dan Pembahasan}

Dalam penelitian ini dipergunakan dua tahap pengujian, tahap pertama adalah Uji Statistik (first order test) yang terdiri dari Uji Parsial (Uji Individual) dan Uji Simultan (Uji Serentak) serta Koefisien Determinasi $\left(\mathrm{R}^{2}\right)$. Tahap kedua adalah Uji Klasik (Second Order Test) yaitu pengujian terhadap penyimpangan Asumsi Klasik dari hasil pengamatan yang terdiri dari Uji Normalitas, Uji Autokorelasi, Uji Heteroskedastisitas, dan Uji Multikolinearitas. 


\section{Uji t ( Uji Parsial)}

Pengujian ini dimaksudkan untuk memperoleh makna hubungan individual atau variabel terikat pertumbuhan ekonomi yang diukur dengan nilai PDRB atas dasar harga berlaku dan variabel bebas (infrastruktur jalan, infrastruktur listrik, dan infrastruktur pendidikan ) secara statistik.

Tabel 6. Hasil Uji t (Uji Parsial) Tahun 2001-2016

\begin{tabular}{|l|l|l|l|l|l|}
\hline \multicolumn{1}{|c|}{ Variabel } & $\begin{array}{c}\text { Koef. } \\
\text { Regresi }\end{array}$ & $\begin{array}{c}\text { Standar } \\
\text { Error }\end{array}$ & $\mathrm{t}_{\text {hitung }}$ & Prob & \multicolumn{1}{c|}{ Keterangan } \\
\hline Konstanta & -12702490 & 8404863. & -1.511326 & 0.1566 & Tidak Signifikan \\
\hline Infra.Jalan & 32623.92 & 17840.20 & 1.828674 & 0.0924 & Signifikan pada $a=10 \%$ \\
\hline Infra. Listrik & 0.007112 & 0.002221 & 3.202367 & 0.0076 & Signifikan pada $a=5 \%$ \\
\hline Infra. Pendidikan & 14226.09 & 30422.77 & 0.467613 & 0.6484 & Tidak Signifikan \\
\hline
\end{tabular}

Sumber: data sekunder diolah (Eviews)

Pada Tabel 6 hasil estimasi dari tahun 2001-2016 bahwa diketahui probabilita $\mathrm{t}_{\text {hitung }}$ pada masingmasing variabel independen atau bebas yaitu infrastruktur jalan $\left(X_{1}\right)$ sebesar 0,0924 , infrastruktur listrik $\left(X_{2}\right)$ sebesar 0,0076 dan infrastruktur pendidikan $\left(\mathrm{X}_{3}\right)$ sebesar 0,6484 bahwa kesimpulan dan interpertasi sebagai berikut :

\section{1) Pengaruh infrastruktur jalan (X1) terhadap pertumbuhan ekonomi yang diukur dengan nilai PDRB atas dasar harga berlaku (Y).}

Berdasarkan hasil nilai probabilita $t_{\text {hitung }}$ pada infrastruktur jalan sebesar 0,0924 dimana nilai probabilita $\mathrm{t}_{\text {hitung }}<10 \%$ atau $(0,0924<0,1)$ maka infrastruktur jalan berpengaruh siginfikan pada pertumbuhan ekonomi yang diukur dengan nilai PDRB atas dasar harga berlaku. Hal ini disebabkan karena jalan merupakan salah satu prasarana penting yang demikian sebagai penghubung dalam kegiatan perekonomian suatu wilayah dimana akan memperlancar arus barang dan jasa antara pusat-pusat produksi dan daerah pemasaran atau sebaliknya (Sjafrijal, 2012:256).

\section{2) Pengaruh infrastruktur listrik (X2) terhadap pertumbuhan ekonomi yang diukur dengan nilai PDRB atas dasar harga berlaku (Y).}

Berdasarkan hasil nilai $t_{\text {hitung }}$ lebih besar dari $t_{\text {tabel }}$ sebesar $(3.202367>2,179)$ atau berdasarkan nilai probabilita $t_{\text {hitung }}$ sebesar 0,0076 pada infrastruktur listrik pada tabel dimana nilai probabilita $t_{\text {hitung }}<5 \%$ dengan demikian $\mathrm{Ha}$ diterima dan $\mathrm{H}_{0}$ ditolak bahwa infrastruktur listrik memiliki pengaruh yang signifikan dalam pertumbuhan ekonomi yang diukur dengan nilai PDRB atas dasar harga berlaku di Kota Mataram.

\section{3) Pengaruh infrastruktur pendidikan (X3) terhadap pertumbuhan ekonomi yang diukur dengan nilai PDRB atas dasar harga berlaku $(Y)$}

Berdasarkan hasil nilai $t_{\text {hitung }}$ lebih kecil dari $t_{\text {tabel }}$ sebesar $(0.467613<2,179)$ atau berdasarkan nilai probabilita $t_{\text {hitung }}$ pada infrastruktur pendidikan sebesar 0,6484 diatas dimana nilai probabilita $t_{\text {hitung }}>5 \%$ dengan demikian diterima $\mathrm{H}_{0}$ dan Ha ditolak bahwa infrastruktur pendidikan tidak memiliki pengaruh yang signifikan pada pertumbuhan ekonomi yang diukur dengan nilai PDRB atas dasar harga berlaku di Kota Mataram. Hal ini disebabkan karena kenaikan atau peningkatan terhadap pembangunan infrastruktur pendidikan tetap atau tidak terjadinya kenaikan atau peningkatan pembangunan pada infrastruktur pendidikan dari tahun 2012-2015 sebesar 343 unit sekolah.

\section{Uji F (Uji Simultan)}

Pengujian secara serentak menunjukan bahwa variabel bebas secara bersama-sama mempunyai pengaruh terhadap varibel terikat.

Tabel 7 Hasil Uji F ( Uji Simultan)

\begin{tabular}{|c|c|}
\hline F-statistik & Prob(F-statistic) \\
\hline 46,37953 & 0,000001 \\
\hline
\end{tabular}

Sumber: data sekunder diolah (Eviews) 
Nilai probabilita $F_{\text {hitung }}=0,000001$ dengan nilai $F_{\text {hitung }}=46,37953$. Berdasarkan hasil perhitungan Eviews diperoleh nilai probabilita $F_{\text {hitung }}<5 \%(0,000001<0,05)$ atau nilai $F_{\text {hitung }}>F_{\text {tabel }}(46,37953>3,49)$. Dengan demikian $\mathrm{H}_{0}$ ditolak dan Ha diterima yang artinya bahwa secara bersama-sama variabel bebas (X) yaitu Infrastruktur Jalan (X1), Infrastruktur Listrik (X2), dan Infrastruktur Pendidikan (X3) secara simultan berpengaruh secara signifikan terhadap Pertumbuhan ekonomi yang diukur dengan nilai PDRB atas dasar harga berlaku (Y) di Kota Mataram tahun 2001-2016 dengan derajat kepercayaan 95\%. Tabel F dalam penelitian ini dapat dilihat pada tabel statistis

\section{Uji Koefisien Determinasi $\mathbf{R}^{2}$}

Untuk mengetahui sejauh mana pengaruh infrastruktur jalan, listrik, dan pendidikan terhadap pertumbuhan ekonomi yang diukur dengan nilai PDRB atas dasar harga berlaku maka dapat diperoleh dari hasil Koefisen Determinasi pada tabel berikut ini.

Tabel 8. Hasil Uji Koefisien Determinasi

\begin{tabular}{|c|}
\hline R-Squared \\
\hline 0,920603 \\
\hline
\end{tabular}

Sumber: Data Sekunder Diolah (Eviews)

Dari hasil estimasi pada Tabel 8 menunjukkan koefisien determinasi $\left(\mathrm{R}^{2}\right)$ sebesar 0,920603 yang berarti bahwa infrastruktur jalan, infrastruktur listrik, dan infrastruktur pendidikan dapat menjelaskan pengaruhi terhadap pertumbuhan ekonomi yang diukur dengan nilai PDRB atas dasar harga berlaku sebesar 92,06\%, sedangkan sisanya sebesar 7,94\% dijelaskan oleh variabel lain yang tidak dianalisis di penelitian ini atau tidak dimasukan kedalam model. Misalnya infrastruktur kesehatan, pengembangan fasilitas pasar modern, penciptaan iklim investasi yang kondusif (Sjafrijal, 2012:294-295).

\section{Interpertasi Statistik}

Berikut merupakan hasil estimasi regresi linear berganda dengan metode OLS menghasilkan persamaan regresi sebagai berikut:

$$
\hat{Y}=-12702490+32623,92 * \mathrm{X} 1+0,00712 * \mathrm{X} 2+14226,09 * \mathrm{X} 3+\mathrm{ei}
$$

Berdasarkan persamaan diatas dapat dijelaskan sebagai berikut :

a). Konstanta $\left(\widehat{\beta}_{0}\right)$

Jika nilai infrastruktur jalan, infrastruktur listrik dan infrastruktur pendidikan atau variabel independen/ bebas tetap atau tidak berubah atau sama dengan nol maka nilai pertumbuhan ekonomi yang diukur dengan nilai PDRB atas dasar harga berlaku (Y) menurun sebesar Rp 12702490,- jutaan.

b). Koefisien Infrastruktur Jalan ( $\beta$ 1)

Koefisien variabel infrastruktur jalan memiliki nilai sebesar 32623,92, dan arah hubungan regresi bertanda positif bermakna bahwa infrastruktur jalan memiliki arah positif terhadap pertumbuhan ekonomi melalui PDRB. Jika infrastruktur jalan mengalami peningkatan 1 satuan (Rp. 1.000.000,-) dengan asumsi variabel lain Cateris Paribus, maka besarnya kenaikan nilai pertumbuhan ekonomi yang diukur dengan nilai PDRB atas dasar harga berlaku (Y) sebesar Rp 32623.92,- jutaan.

c). Koefisien Infrastruktur Listrik ( $\beta 2$ )

Koefisien variabel infrastruktur listrik memiliki nilai sebesar 0,00711182599338, dan arah hubungan regresi bertanda positif bermakna bahwa infrastruktur listrik memiliki arah positif terhadap pertumbuhan ekonomi melalui PDRB. Jika infrastruktur listrik mengalami peningkatan 1 satuan (Rp. 1.000.000,-) dengan asumsi variabel lain Cateris Paribus, maka besarnya kenaikan nilai pertumbuhan ekonomi yang diukur dengan nilai PDRB atas dasar harga berlaku (Y) sebesar Rp 0,00711182599338, - jutaan.

d). Koefisien Infrastruktur pendidikan $(\beta 3)$

Koefisien variabel infrastruktur pendidikan memiliki nilai sebesar 14226,0903275, dan arah hubungan regresi bertanda positif bermakna bahwa infrastruktur pendidikan memiliki arah positif terhadap pertumbuhan ekonomi melalui PDRB. Jika infrastruktur listrik mengalami peningkatan 1 satuan (Rp. 1.000.000,-) dengan asumsi variabel lain Cateris Paribus, maka akan meningkatkan nilai pertumbuhan ekonomi yang diukur dengan nilai PDRB atas dasar harga berlaku (Y) sebesar Rp 14226,0903275- jutaan. 


\section{Interpertasi Ekonomi}

Berdasarkan hasil estimasi pada penelitian ini mengenai pengaruh infrastruktur jalan, infrastruktur listrik dan infrastruktur pendidikan dapat dijelaskan sebagai berikut:

\section{Infrastruktur Jalan}

Pengaruh infrastruktur jalan terhadap pertumbuhan ekonomi yang diukur dengan nilai PDRB atas dasar harga berlaku bertanda positif dan signifikan. Menurut Sjafrijal, 2012 mengatakan infrastruktur jalan sebagai pendorong dalam pertumbuhan ekonomi dalam memperlancar arus barang dan jasa antara pusat-pusat produksi dan daerah pemasaran. Dilihat dari hasil empiris dan teori bila dibandingkan dan dihubungkan maka mendukung hasil teori dengan demikian membenarkan teori dengan harapan tanda positif (+) dengan hasil uji signifikan dan terbukti. Dengan demikian untuk tetap meningkatkan pertumbuhan ekonomi maka pemerintah harus terus memperhatikan dan meningkatkan infrastruktur jalan sehingga dapat menunjang mobilisasi dalam penyaluaran produksi barang dan jasa.

Hasil penelitian ini searah dengan penelitian yang dilakukan oleh Hapsari (2011), Andriani (2013), Lek (2014), Fauzani (2014), Uzzahro (2014), Hasti (2015), Warsilan (2015), Ahmad (2016), Widianingtyas (2018) yang menyatakan bahwa infrastruktur jalan memiliki pengaruh yang positif dan signifikan terhadap ekonomi. Sedangkan penelitian lain yang dilakukan menyatakan bahwa variabel infrastruktur jalan memiliki pengaruh yang positif dan tidak signifikan terhadap pertumbuhan ekonomi, sehingga yang menjadi pembeda adalah taraf signifikan. Penelitian-penelitian tersebut antara lain dilakukan oleh, Harry (2014), Arafah (2017), Nurul (2017) yang menyatakan bahwa infrastruktur jalan memiliki pengaruh yang positif dan tidak signifikan terhadap pertumbuhan ekonomi. Dan penelitian oleh Desty (2014) menyatakan bahwa infrastruktur jalan memiliki pengaruh yang negatif dan tidak signifikan terhadap pertumbuhan ekonomi.

\section{Infrastruktur Listrik}

Pengaruh infrastruktur listrik terhadap perumbuhan ekonomi yang diukur dengan nilai PDRB atas dasar harga berlaku bertanda positif dan signifikan. Menurut penelitian Arafah, 2017 bahwa kebutuhan listrik menjadi tuntutan primer yang harus dipenuhi, tidak hanya untuk rumah tangga namun juga untuk kegiatan ekonomi terutama industri. Dalam kehidupan masyarakat yang semakin modern, semakin banyak peralatan rumah tangga, peralatan kantor serta aktivitas-aktivitas masyarakat yang mengandalkan sumber energi dari listrik. Peningkatan kegiatan ekonomi dalam produksi dan investasi juga membutuhkan listrik yang memadai. Oleh karena itu permintaan listrik rmeningkat dari tahun ke tahun baik dari segi kuantitasnya maupun kualitasnya. Serta menurut development Report (1994) berperan penting dalam peningkatan pertumbuhan ekonomi, wilayah dengan tingkat ketersediaan infrastruktur yang mencukupi akan mengalami pertumbuhan ekonomi yang lebih tinggi dimana peningkatan dilakukan pada infrastruktur dasar salah satunya adah listrik. Dilihat dari hasil empiris dan teori bila dibandingkan dan dihubungkan maka mendukung hasil teori dengan demikian membenarkan teori dengan harapan tanda positif (+) dengan hasil uji signifikan dan terbukti.

Hasil penelitian ini searah dengan penelitian yang dilakukan oleh Abdul (2011), Hapsari (2011), Andriani (2013), Ahmad (2016), Wibowo (2016), Nurul (2017), Widianingtyas (2018) yang menyatakan bahwa variabel infrastruktur listrik memiliki pengaruh yang positif dan signifikan terhadap pertumbuhan ekonomi. Sedangkan penelitian lain yang dilakukan menyatakan bahwa variabel infrastruktur listrik memiliki pengaruh yang positif dan tidak signifikan terhadap pertumbuhan ekonomi, sehingga yang menjadi pembeda adalah taraf signifikan. Penelitian-penelitian tersebut antara lain dilakukan oleh, Desty (2014), Fauzani (2014), Harry (2014), Arafah (2017), yang menyatakan bahwa infrastruktur listrik tidak mempengaruhi pertumbuhan ekonomi.

\section{Infrastruktur Pendidikan}

Pengaruh infrastruktur pendidikan terhadap perumbuahan ekonomi yang diukur dengan nilai PDRB atas dasar harga berlaku bertanda positif (+) dan tidak signifikan, menurut Ernisusiyawati, 2013 dalam Arafah (2017:19) bahwa Pendidikan merupakan salah satu faktor dominan dalam mengupayakan pembangunan suatu negara secara optimal. Melalui pendidikan yang bermutu akan menghasilkan Sumber Daya Manusia yang memiliki pengetahuan yang tinggi serta mampu mengimpelemntasikannya secara optimal sehingga mampu memberikan sumbangan terhadap kemajuan dan produktivitas ekonomi yang akan berdampak pada pertumbuhan ekonomi. suatu daerah atau wilayah. Dilihat dari hasil empiris dan teori bila dibandingkan dan dihubungkan maka tidak mendukung teori dengan hasil uji tidak signifikan. Hal ini terjadi karena peningkatan pada infrastruktur pendidikan tidak mengalami kenaikan dalam hal 
pembangunan yang di lakukan di Kota Mataram yang dimana dari tahun 2012-2015 infrastruktur pendidikan tetap dalam pembangunan sehingga berdampak pada pengaruh peningkatan pertumbuhan ekonomi dari sisi nilai PDRB atas dasar harga berlaku dalam hal ini maka untuk peningkatan pertumbuhan ekonomi dari sisi nilai PDRB Kota Mataram harus tetap diperhatikan dan ditingkatkan guna untuk perbaikan prasarana pendidikan yang lebih baik yang secara langsung dapat meningkatkan pertumbuhan dari sisi nilai PDRB itu sendiri pada saat dilakukannya penambahan pembangunan infrastruktur pendidikan itu sendiri.

Hasil penelitian ini searah dengan penelitian yang dilakukan oleh Rindang (2009) yang menyatakan bahwa infrastruktur pendidikan memiliki pengaruh yang positif dan tidak signifikan terhadap pertumbuhan ekonomi. Sedangkan penelitian lain yang dilakukan menyatakan bahwa variabel infrastruktur pendidikan memiliki pengaruh yang positif dan signifikan terhadap pertumbuhan ekonomi, sehingga yang menjadi pembeda adalah taraf signifikan. Penelitian-penelitian tersebut antara lain Wahyuni (2009), Arafah (2017), Fauzani (2014), Uzzahro (2014), Hasti (2015), Wibowo (2016), Nurul (2017), Widianingtyas (2018), yang menyatakan bahwa infrastruktur pendidikan memiliki pengaruh yang positif dan signifikan terhadap pertumbuhan ekonomi.

\section{Pengaruh Variabel secara Bersama-sama (Simultan)}

Secara bersama-sama, Infrastruktur jalan, Infrastruktur Listrik dan Infrastruktur pendidikan memiliki pengaruh yang signifikan terhadap Pertumbuhan ekonomi yang diukur dengan nilai PDRB atas dasar harga berlaku (Y) di Kota Mataram dapat diketahui dari probabilitas F statistik yang bernilai 0,000001 dengan nilai $\mathrm{F}$ hitung sebesar berada diatas nilai $\mathrm{F}$ tabel pada taraf signifikansi $\alpha=5 \%(0,05)$ sebesar $(46,37953>3,49)$. Hal ini berarti semua variabel bebas berpengaruh signifikan terhadap pertumbuhan ekonomi yang diukur dengan nilai PDRB atas dasar harga berlaku di Kota Mataram. Yang berarti Kenaikan dari infrastruktur jalan, infrastruktur listrik dan infrastruktur pendidikan akan mempengaruhi pertumbuhan Ekonomi. Besarnya kontribusi dari semua variabel bebas tercermin dari nilai koefisien determinan $\mathrm{R}^{2}$ sebesar $0,920603(92,06 \%)$ yang berarti bahwa variabel terikat Pertumbuhan ekonomi yang diukur dengan nilai PDRB atas dasar harga berlaku di Kota Mataram dipengaruhi sebesar oleh variabel bebas yakni Infrastruktur jalan, infrastruktur listrik dan infrastruktur pendidikan. Sedangkan sisanya sebesar 7,94\% dipengaruhi oleh variabel diluar model yang tidak dimasukan di dalam penelitian ini.

\section{SIMPULAN DAN SARAN}

\section{Simpulan}

Penelitian ini bertujuan untuk meneliti seberapa besar pengaruh infrastruktur jalan, infrastruktur listrik, infrastruktur pendidikan dan infrastruktur kesehatan terhadap pertumbuhan ekonomi yang diukur dengan nilai PDRB atas dasar harga berlaku di Kota Mataram tahun 2001 - 2016. Berdasarkan hasil dan pembahasan yang telah dijelaskan pada bab sebelumnya, maka dapat disimpulkan :

1. Infrastruktur jalan secara parsial berpengaruh signifikan terhadap pertumbuhan ekonomi yang diukur dengan nilai PDRB atas dasar harga berlaku di Kota Mataram dengan hasil estimasi diperoleh nilai probabilita $\mathrm{t}_{\text {hitung }}<a=10 \%$ yaitu sebesar $(0,0924<0,1)$.

2. Infrastruktur listrik secara parsial berpengaruh signifikan terhadap pertumbuhan ekonomi yang diukur dengan nilai PDRB atas dasar harga berlaku di Kota Mataram dengan hasil estimasi diperoleh nilai probabilita $t_{\text {hitung }}<5 \%$ atau sebesar $(0,0076<0,05)$.

3. Infrastruktur pendidikan terhadap pertumbuhan ekonomi berpengaruh tidak signifikan dengan berdasarkan hasil estimasi diperoleh nilai probabilita $t_{\text {hituung }}>0,05$ atau sebesar $(0,6484>0,05)$.

4. Dari hasil uji F bahwa variabel bebas yaitu infrastruktur jalan, infrastruktur listrik dan infrastruktur pendidikan mempunyai pengaruh secara signifikan terhadap pertumbuhan ekonomi dari sisi nilai PDRB atas dasar harga berlaku secara bersama-sama dengan nilai probabilita $F_{\text {hitung }}<0,05$ yaitu sebesar $(0,000001<0,05)$. 


\section{Saran -saran}

Berdasarkan kesimpulan yang ada dalam penelitian ini maka didapatkan saran sebagai berikut:

1. Berdasarkan hasil penelitian yang dilakukan tentang pengaruh infrastruktur jalan, infrastruktur listrik, infrastruktur pendidikan, dan infrastruktur terhadap pertumbuhan ekonomi yang diukur dengan nilai PDRB atas dasar harga berlaku di Kota Mataram bahwasannya dari pihak pemerintah dimana infrastruktur memiliki pengaruh yang positif terhadap pertumbuhan ekonomi sehingga ketersediaan infrastruktur perlu mendapat perhatian yang lebih serius dari pemerintah salah satunya infrastruktur jalan dan infrastruktur listrik yang memiliki pengaruh cukup besar terhadap pertumbuhan ekonomi di Kota Mataram dengan terus meningkatkan perbaikan infrastruktur jalan yang mengalami kerusakan, dalam peningkatan infrastruktur listrik maka perlu adanya kerjasama antara pihak PT. PLN dan pihak pemerintah Kota Mataram serta pihak swasta agar daya listrik semakin ditingkatkan, dengan cara penyediaan energi listrik alternatif sehingga mampu memenuhi kebutuhan industri dan rumah tangga guna mendukung pertumbuhan ekonomi sehingga mampu menarik para investor untuk berinvestasi di Kota Mataram.

2. Pihak pemerintah harus lebih aktif didalam meningkatkan infrastruktur pendidikan bagi masyarakat dengan memberikan peningkatan baik sarana dan prasarana pendidikan di sekolah yang ada di Kota Mataram agar bisa menciptakan masyarakat yang lebih mampu dalam meningkatkan kualitas hidupnya dengan adanya pendidikan yang lebih baik.

3. Untuk pengembangan studi berikutnya perlunya ditambahkan atau digunakan variabel-variabel lain sebagai proksi dalam menjelaskan pertumbuhan ekonomi yang diukur dengan nilai PDRB atas dasar harga berlaku Kota Mataram misalnya variabel infrastruktur air bersih, yang digunakan sebagai input untuk menghasilkan ouput dalam penggunaan proses produksi yang kegiatan ekonomi serta variabel infrastruktur kesehatan.

\section{DAFTAR PUSTAKA}

Adisasmita, Rahardjo. 2005. Teori-Teori Pembangunan Ekonomi ; Pertumbuhan Ekonomi dan Pertumbuhan Wilayah. Graha Ilmu. Yogyakarta

Abdul, Rmaqin. 2011. Pengaruh Kondisi Infrastruktur Terhadap Pertumbuhan Ekonomi Di Jawa Barat. Jurnal Fakultas Ekonomi. Universitas Pasundan

Agung. 2016. Pengaruh Infrastruktur Ekonomi Dan Sosial Terhadap Pertumbuhan Ekonomi Di Indonesia Tahun 2006-2013. Skripsi fakultas ekonomi.Universitas Negeri Yogyakarta. Yogyakarta.

Andriani, Evanti. 2013. Analisis Peran Infrastruktur Terhadap Pertumbuhan Ekonomi di Provinsi Jawa Barat. Skripsi Fakultas Ekonomi dan Manajemen. Institut Pertanian Bogor. Bogor.

Anonim 2005. Peraturan Presiden Republik Indonesia Nomor 67 Tahun 2005. Kerjasama Pemerintah Dengan Badan Usaha Dalam Penyediaan Infrastruktur.

Amirudin, Ahmad. 2016. Analisis Pengaruh Infrastruktur Terhadap Pertumbuhan Ekonomi Di Provinsi Sumatra Barat Tahun 2008-2013. Tesis. Fakultas Ekonomi Dan Bisnis. Universitas Gadjah Mada Yogyakarta. Yogyakarta.

Arafah. 2017. Analisis Pengaruh Infrastruktur Jalan, Listrik dan Pendidikan Terhadap Pertumbuhan Ekonomi Di Kota Medan. Fakultas Ekonomi Dan Bisnis. Universitas Lampung. Lampung

Aringga ,Hasti. 2015. Pengaruh Pembangunan Infrastruktur Terhadap Pendapatan Regional Kabupaten Jember. Jurnal Fakultas Ekonomi. Universitas Jember. Jember.

Badan Pusat Statistik, 2004-2017. Pertumbuhan Ekonomi Kota Mataram. BPS Kota Mataram.

Badan Pusat Statistik, 2001-2017. PDRB Kota Mataram Berdasarkan Harga Berlaku Menurut Lapangan Usaha . BPS Kota Mataram.

Badan Pusat Statistik, 2001-2017. Kota Mataram dalam Angka. BPS Kota Mataram.

Bangun, Rindang. 2009. Pengaruh Infrastruktur Ekonomi Pada Pertumbuhan Ekonomi Di Wilayah Indonesia. Jurnal. Departemen Ilmu Ekonomi Dan Manajemen, Institut Pertanian Bogor. Bogor.

Edwin. 1998. Analisis Sifat Pemukiman Terhadap Prasarana Umum Daerahnya. Tesis. Program Pasca Sarjana, Institut Pertanian Bogor. Bogor.

Gujarati, Damanor. 2003. Ekonometrika Dasar Jilid 1.Erlangga. Jakarta

.2006. Ekonometrika Dasar Jilid 2. Erlangga. Jakarta 
Hapsari, Tanjung. 2011. Pengaruh Infrastruktur Terhadap Pertumbuhan Ekonomi Di Indonesia. Fakultas Ekonomi dan Bisnis \{Skripsi\}, UIN Syarif Hidayatullah, Jakarta.

Jhingan, ML. 2000. Ekonomi Pembangunan dan Perencanaan. PT. Raja Grafindo Persada. Jakarta

KBBI. 2008. Kamus Besar Bahasa Indonesia (KBBI). (Online) Available at: http://kbbi.web.id/pendidikan [ Diakses 21 juni 2018]

Kodotie, R. J. 2003. Manajemen dan Rekayasa Infrastruktur. Pustaka Pelajar, Yoyakarta.

Kurniadi, Harry. 2014. Pengaruh Peningkatan Infrastruktur Terhadap Pertumbuhan Ekonomi Di Kota Sibolga. Jurnal Fakultas Ekonomi. Sumatra Utara

Lek, Mesak. 2013. Analisis Dampak Pembangunan Jalan Terhadap Pertumbuhan Usaha Ekonomi Rakyat Di Pedalaman May Barat Provinsi Papua Barat. Fakultas Ekonomi dan Bisnis, Universitas Cendrawasi, Jayapura.

Mankiw, N.gregory. 2000. Teori makro ekonomi.ed.4,: penerbit Erlangga Jakarta 2007. Teori makro ekonomi. penerbit Erlangga Jakarta

Nurhidayanti C, Desty. 2014.Pengaruh Infrastruktur Terhadap Pertumbuhan Ekonomi Di Kota Sukabumi Tahun 1990-2012. Skripsi Fakultas Ekonomi dan Manajemen. Institut Pertanian Bogor. Bogor.

Nurul. 2017. Pengaruh Infrastruktur Terhadap Pertumbuhan Ekonomi Di Provinsi Daerah Istimewa Yogyakarta. Fakultas Ekonomi dan Bisnis. Universitas Yogyakarta. Yogyakarta.

Prathama Rahardja. 2008. Teori Ekonomi Makro Suatu Pengantar. Ed. 4, FEUI Jakarta

Pramono, Adi. 2011. Pengaruh Pembangunan Infrastruktur Jalan Dan Listrik Terhadap Pertumbuhan Ekonomi Di Kalimatan Tahun 1994-2008. Tesis Fakultas Ekonomi. Universitas Indonesia. Jakarta.

Rencana Pembangunan Menengah Daerah (RPJMD). Kota Mataram. Lokasi Kota Mataram dalam Peta Provinsi NTB.

NTB.

(RPJMD). Kota Mataram. Peta Wilayah Kota Mataram dalam Peta Provinsi

Sjafrizal. 2012. Ekonomi Wilayah dan Perkotaan. PT Raja Grafindo Persada Jakarta

Stone. 2003. Infrastruktur Sebagai Fasilitas Fisik. Fakultas Ekonomi dan Bisnis. Universitas Bangka Belitung. Bangka Belitung.

Sugiono. 2006. Metode Penelitia Kuantitatif. Kuantitatif dan $R \&$ D. Alfabeta. Bandung

Suliyanto. 2005. Anakisis Data Dalam Aplikasi Pemasaran. Ghalia. Bogor

Tarigan, Robinson. 2014. Ekonomi Regional Teori dan Aplikasi. PT. Bumi Aksara :Jakarta.

Todaro, Michael P dan Stephen C Smith 2004. Pembangunan ekonomi dunia Ketiga Edisi Pertama. Erlangga Jakarta

2006. Pembangunan ekonomi. Edisi Kesembilan Jilid I. Erlangga Jakarta

Tri Wahyuni, Krismanti, 2009. Analisis Pengaruh Infrastruktur Ekonomi dan Sosial Terhadap Produktivitas Ekonomi di Indonesia. Skripsi Fakultas Ekonomi dan Manajemen. Institut Pertanian Bogor. Bogor.

The World Bank. 1994. World Development Report: Infrastructure For Development. Oxford University Press, New York.

Uzzahroh, Alfinna. 2014. Sistem Pendukung Keputusan Penentuan Alokasi Perbaikan Infrastruktur Dengan Metode AHP. Skripsi Fakultas Ekonomi. Universitas Indonesia. Jakarta.

Warsilan. 2015. Peranan Infrastruktur Terhadap Pertumbuhan Ekonomi Dan Implikasi Pada Kebijakan Pembangunan Di Kota Samrinda. Jurnal Fakultas Ekonomi. Universitas Samarinda. Samarinda.

Wibowo. Agung 2015. Pengaruh Infrastruktur Ekonomi Dan Sosial Terhadap Pertumbuhan Ekonomi Di Indonesia Tahun 2006-2013. Skripsi FEB. Universitas Diponegoro. Semarang

Widarjono, Agus, 2017. Ekonomitrika Pengantar dan Aplikasinya Disertai Panduan Eviews. Penerbit:UPP STIM YKPN.

Widianingtyas, Fitria. 2018. Pengaruh Infrastruktur Ekonomi Dan Sosial Terhadap Pertumbuhan Ekonomi Di Wilayah Jawa Dan Sumatera Tahun 2008-2015. Skripsi Fakultas Ekonomi Dan Bisnis Islam. Universitas Islam Negeri Sunan Kalijaga Yogyakarta. Yogyakarta.

Zamzami, Fauzani. 2014. Analisis Pengaruh Infrastruktur Terhadap PDRB Jawa Tengah. Skripsi FEB. Universitas Diponegoro. Semarang. 